\title{
Patterns of Transfusion Transmitted Infection in Past Ten Years Among Voluntary Blood Donors In Chennai- A Cross Sectional Study
}

\author{
S.T.Radhiga ${ }^{1}$, P.Arumugam ${ }^{1}$, S.Kalpana ${ }^{2}$ and Mayil Vahanan Natarajan ${ }^{3}$ \\ ${ }^{1}$ Department of Transfusion Medicine, ${ }^{2}$ Department of Epidemiology, ${ }^{3}$ Vice-Chancellor, The Tamil Nadu \\ Dr.M.G.R.Medical University, Guindy, Chennai, Tamil Nadu, India.
}

\begin{abstract}
Background: Transfusion transmitted infection (TTI) is a major challenge to the transfusion services all over the world and a major problem in India. The problem of TTI is directly proportionate to the prevalence of the infections in the Blood donor community. It has been made Mandatory to screen for HIV, $H B V, H C V$, SYPHILIS and MALARIA in India. Hepatitis B and C infections are prevalent in India and carrier rate is about $1-5 \%$ and $1 \%$, respectively. Because of low viraemia and the mutant strains are undetectable by routine ELISA, Incidence of Post transfusion hepatitis B\&C in India is about 10\% only.HIV prevalence among blood donors is different in various parts of the country. . The Department of Transfusion Medicine, at Tamilnadu Dr.M.G.R.Medical University through Voluntary blood donation camps, collected 25,000 number of blood units for the past ten years from 2001 - 2012.Methods: Five ml of blood was collected from each donor, the serum was separated and subjected to screening for "HIV,HBV,HCV, SYPHILIS and MALARIA".. The methods used were ELISA techniques for "HIV, HBV and HCV". Detection for malarial parasites was done by thick film examination and for syphilis, VDRL method was used. Results: Out of 25,000 donors, HIV was $0.01 \%, H C V-0.08 \%$, HBsAg $0.74 \%$ and VDRL Reactivity was $0.03 \%$. None of them were positive for Malaria. Conclusion: Proper vigilance and quality control is needed to prevent this problem. Current syphilis tests may not be sensitive but it should be continued to exclude high-risk donors. Malaria is a real problem for India due to the lack of a simple and sensitive screening test. Total dependence of altruistic repeat voluntary donors and use of sensitive laboratory tests may help Indian blood transfusion services to reduce the incidences of TTIs.
\end{abstract}

Key words: Transfusion Transmitted Infection, HIV, HCV, VDRL.

\section{Introduction}

Transfusion transmitted diseases (TTI) are a great concern of safety for patients The magnitude of the TTI varies from country to country depending on loads in that particular population There is a risk of 1-2 per 1000 recipients receiving contaminated blood with viral, bacterial or parasitic agents. The Indian subcontinent is classified as an intermediate Hepatitis B Virus (HBV) endemic (HBsAg) zone and has the second largest global pool of chronic HBV infections. The risk of transfusion transmission of these viruses may be alarming due to high seroprevalence of HIV, anti-HCV, and HBsAg among blood donors.

The objective of this study is to estimate the seroprevalence of transfusion transmitted diseases among Voluntary blood donors at the Tamil nadu Dr.M.G.R.Medical University. This knowledge might give us an idea of transfusion transmitted disease burden of the voluntary blood donors and the basic epidemiology of these diseases in the community.

\section{Methods}

A cross sectional study was conducted at the Department of Transfusion Medicine, Chennai. Data were collected for a period of 10 years from January 2001 to June 2012. A total of 25395 blood was collected and studied. Each donor blood sample was screened for HIV, HBsAg, HCV, and syphilis and malaria. Exclusion criteria for blood donation were current history of medication, recent history of having undergone a surgical procedure, serious illness, recent blood transfusions, weight $<45 \mathrm{~kg}$, age $<18$ and $>60$ years, anemic, pregnant and lactating women. The outcome variable was serological status of the selected individual, whether positive or negative for any TTIs, which was determined from the blood sample.

\section{Sample collection and laboratory testing}

Five $\mathrm{ml}$ of blood was collected from each donor in a plain, sterile test tube after obtaining informed consent. Blood samples were centrifuged and the sera were separated and used for screening. Samples were analyzed for antibodies to HIV,HBsAg and HCV by ELISA. Test for syphilis was done by VDRL and malaria by thick and thin slide method. The validity of the test is assured as per the given criterion and the results were computed. 


\section{Statistical analysis}

The data entry was carried out using Microsoft Office Excel worksheet and percentage and proportions for each variable was calculated.

\section{Results}

Out of total 25395 voluntary blood donors from 2001 - June 2012, Male were in the percentage of 78 to 95 and Females were in the percentage of 5-22, which shows predominance of males as compared to females for the studied years [Table 1]

\begin{tabular}{|l|l|l|l|}
\hline Year & Male & Female & Total \\
\hline 2001 & $78 \%$ & $22 \%$ & 2400 \\
\hline 2002 & $90 \%$ & $10 \%$ & 2580 \\
\hline 2003 & $92 \%$ & $8 \%$ & 2475 \\
\hline 2004 & $89 \%$ & $11 \%$ & 2040 \\
\hline 2005 & $90 \%$ & $10 \%$ & 2100 \\
\hline 2006 & $85 \%$ & $15 \%$ & 2540 \\
\hline 2007 & $87 \%$ & $13 \%$ & 2768 \\
\hline 2008 & $95 \%$ & $5 \%$ & 2478 \\
\hline 2009 & $92 \%$ & $8 \%$ & 2666 \\
\hline 2010 & $80 \%$ & $20 \%$ & 2753 \\
\hline $\begin{array}{l}2012 \\
\text { June }\end{array}$ & $90 \%$ & $10 \%$ & 595 \\
\hline
\end{tabular}

The prevalence of HBsAg, HCV, VDRL, and HIV among voluntary blood donors in the study population is showed in [ Table-2]. The overall seroprevalence of HBsAg was 187, $(0.74 \%)$ and HCV was positive in 21 donors $(0.08 \%)$, VDRL was positive in 8 donors $(0.03 \%)$ and HIV was $0.01 \%$. The highest prevalence was observed for HBV followed by HCV, syphilis and HIV in decrease.

Table: 2 Year Wise Distribution of Transfusion Transmitted Disease

\begin{tabular}{|l|l|l|l|l|l|}
\hline Year & HCV & HBsAg & VDRL & HIV & Total \\
\hline $\mathbf{2 0 0 1}$ & $1(.04 \%)$ & $5(.2 \%)$ & Nil & Nil & 2400 \\
\hline $\mathbf{2 0 0 2}$ & $2(.07 \%)$ & $26(1 \%)$ & Nil & Nil & 2580 \\
\hline $\mathbf{2 0 0 3}$ & Nil & $26(1 \%)$ & $1(.04 \%)$ & Nil & 2475 \\
\hline $\mathbf{2 0 0 4}$ & $1(.04 \%)$ & $9(.4 \%)$ & Nil & Nil & 2040 \\
\hline $\mathbf{2 0 0 5}$ & $1(.04 \%)$ & $8(.4 \%)$ & $3(.14 \%)$ & Nil & 2100 \\
\hline $\mathbf{2 0 0 6}$ & Nil & $14(.6 \%)$ & Nil & Nil & 2540 \\
\hline $\mathbf{2 0 0 7}$ & $1(.03 \%)$ & $26(.9 \%)$ & Nil & Nil & 2768 \\
\hline $\mathbf{2 0 0 8}$ & $2(.08 \%)$ & $25(1 \%)$ & $1(.04 \%)$ & Nil & 2478 \\
\hline $\mathbf{2 0 0 9}$ & $7(.3 \%)$ & $26(1 \%)$ & $1(.04 \%)$ & $3(.1 \%)$ & 2666 \\
\hline $\mathbf{2 0 1 0}$ & $5(.2 \%)$ & $19(.7 \%)$ & $2(.07 \%)$ & Nil & 2753 \\
\hline $\begin{array}{l}\mathbf{2 0 1 2} \text { till } \\
\text { June }\end{array}$ & $1(.2 \%)$ & $3(.5 \%)$ & Nil & Nil & 595 \\
\hline
\end{tabular}

With respect to the individual TTI, it is observed that the prevalence of HBV was $23 \%$ below at the age groups > 20 years (100\%), HCV within the age group between 31 and 40 years (43.90\%), syphilis within the age group between 41 and 50 years (16.66\%) and HIV between 21 and 30 years $(6.34 \%)$. The difference of the prevalence of transfusion transmitted diseases among different age groups was statistically not significant $(P>0.05)$. While observing the pattern of TTI among blood donors in the past ten years, it shows that HCV was detected less in the year 2001 but it was high 2009-10. Considering HBsAg, it was almost similar from 2002 to 2010. VDRL was nil from 2001 to 2008 and even in 2009 -2012 less case was detected. In the past ten years, only one case was detected in HIV. It shows that there was no pattern seen in TTI for the past ten years. 
Table:3 Distribution of Transfusion Transmitted infections according to age group.

\begin{tabular}{|c|c|c|c|c|c|c|c|c|}
\hline \multirow{2}{*}{$\begin{array}{l}\text { Age } \\
\text { in } \\
\text { years }\end{array}$} & \multicolumn{2}{|c|}{$\mathrm{HBsAg}$} & \multicolumn{2}{|c|}{$\mathrm{HCV}$} & \multicolumn{2}{|c|}{ HIV } & \multicolumn{2}{|c|}{ VDRL } \\
\hline & No & $\%$ & No & $\%$ & No & $\%$ & No & $\%$ \\
\hline$>20$ & 43 & 22.991 & 9 & 42.85 & 01 & 0.003 & 4 & 50 \\
\hline $21-30$ & 79 & 42.24 & 6 & 28.57 & 02 & 0.006 & 4 & 50 \\
\hline $31-40$ & 65 & 34.75 & 5 & 23.80 & - & - & - & - \\
\hline $41-50$ & - & - & 1 & 4.76 & - & - & - & -- \\
\hline$<51$ & - & - & - & - & - & - & - & - \\
\hline
\end{tabular}

As mentioned in [Table-4] that the prevalence of HBV and HCV was higher among Males $(84 \%, 61 \%$, ) as compared to Females $(16 \%, 39 \%)$ respectively, while for HIV and VDRL it was higher among Females $(67 \%, 63 \%)$ as compared to Males $(33 \%, 37 \%)$, the difference of prevalence by sex was statistically significant $(P<0.05)$.

Table -4 Distribution of sex

\begin{tabular}{|l|l|l|l|l|}
\hline Sex & HBsAg & HCV & HIV & VDRL \\
\hline Male & $157(84 \%)$ & $13(61 \%)$ & $1(33 \%)$ & $3(37 \%)$ \\
\hline Female & $30(16 \%)$ & $8(39 \%)$ & $2(67 \%)$ & $5(63 \%)$ \\
\hline
\end{tabular}

\section{Discussion}

Blood and blood products is an integral and life-saving procedure of modern medicine, but simultaneously it carries the risk of transmitting the life threatening transfusion transmissible infectious. They are transmitted parenterally, vertically, or through high-risk sexual behaviors and can cause fatal acute and chronic life-threatening disorders. Blood transfusion is a potential route of transmission of these TTIs. ${ }^{3,4}$

Screening of blood is now mandatory for many diseases and is undertaken routinely in blood banks. Transmission of TTIs during the serologically window period still poses a threat to blood safety in environments where there is high rate of TTIs. The prevalence of TTIs among the Indian blood donors is reported to be ranging as follows; $\mathrm{HBV}-0.66 \%$ to $12 \%, \mathrm{HCV}-0.5 \%$ to $1.5 \%$, HIV- $0.084 \%$ to $3.87 \%$, and syphilis $-0.85 \%$ to $3 \%$ respectively ${ }^{5}$ but in our study the findings shows that prevalence of TTIs is as follows: HBV $0.2 \%$ to $1 \%$, HCV0.04\%to $0.2 \% \mathrm{HIV}$ was $0.1 \%$ syphilis $0.04 \%-0.1 \%$. The present study revealed seroprevalence of HBV at $1 \%$ among the donors which is similar to findings by Kaur et al. ${ }^{6}$ and Singh B et al.., ${ }^{7}$ Variable results of $0.66 \%,{ }^{8} 2.45 \%,{ }^{9} 3.44 \%,{ }^{10} 5.86 \%,{ }^{11} 25 \%{ }^{12}$ have also been reported in various other studies.

$\mathrm{HCV}$ infection is an evolving public health problem globally. For hepatitis $\mathrm{C}$, the estimated prevalence in this study was 0.04 to $0.3 \%$, reported by the other studies $0.79 \%,{ }^{5} 0.88 \%{ }^{13}$ and $0.78 \%{ }^{9}$; whereas a few studies reported much lower level of prevalence such as $2.8 \%,{ }^{14}$ and $6.21 \%{ }^{15}$ and a yet another set of studies reported it to be at higher levels of $0.28 \%{ }^{16}$ and $0.50 \% .{ }^{7}$ Transmission of HCV is primarily through blood exposure and majority of the infected person's progress to chronic infection and chance of cirrhosis and hepatocellular carcinoma is more as compared to HBV. Blood is one of the main sources of transmission of Hepatitis C; hence, donor selection is of paramount importance. In the present study, the prevalence of HIV was found to be $0.1 \%$. But it is slightly less in study done by Gupta et al., ${ }^{7}$ and Tiwari et al. ${ }^{17}$, reported $0.084 \%$ and $0.054 \%$ prevalence of HIV among blood donors, whereas lower seroprevalence of $0.0 \%{ }^{18}$ and higher seroprevalence of $0.13 \%,{ }^{13} 0.19 \%,{ }^{15} 0.47 \%,{ }^{10} 3.8 \%{ }^{16}$ and $11.7 \%{ }^{12}$ have been reported.

For syphilis, the seroprevalence was found to be $0.07 \%$ in the present study, which was much lower than reported by other studies $0.85 \%^{8}$ and $1.2 \% .^{11}$ Regarding sex, the study found that blood transfusion transmitted diseases are more prevalent among males than females, the difference of prevalence by sex was statistically significant $(P<0.05)$, which was comparable to other studies ${ }^{11}$. A sex-wise difference in seroprevalence might be due to differences in the risk behavior. Effective control strategies including a sensitive and stringent screening of all blood donors, public awareness programs, and institution of adequate public health measures are urgently needed.

\section{Conclusion}

Blood is still one of the main sources of transmission of hepatitis B, hepatitis C, HIV, and syphilis. The majority of donors in our country are voluntary, relatives or friends, who are apparently healthy, but this study 
found that these diseases are prevalent among donors. Hence, strict selection of blood donors with the emphasis on getting voluntary donors and comprehensive screening of donors for TTIs using standard methods are highly recommended to ensure the safety of blood for recipient.

\section{References}

[1]. Lavanchy D. Hepatitis B virus epidemiology, disease burden, treatment, and current and emerging prevention and control measures: A review. J Viral Hepat 2004; 11:97-107.

[2]. Nancy Singh. NAT: Safe Blood, Safe India. Available from: http://www.expresshealthcare.in/200810/knowledge02.shtml. [Last accessed on 2011 Dec 09].

[3]. Irshad M, Peter S. Spectrum of viral hepatitis in thalassemic children receiving multiple blood transfusions. Indian J Gastroenterol $2002 ; 21: 183-4$

[4]. Mollah AH, Nahar N, Siddique MA, Anwar KS, Hassan T, Azam MG. Common transfusion-transmitted infectious agents among thalassaemic children in Bangladesh. J Health Popul Nutr 2003;21:67-71.

[5]. Chattoraj A, Bhel R, Kataria V. Infectious disease markers in blood donors. Med J Armed Forces India 2008;64(1):33-5

[6]. Kaur H, Dhanon J, Pawar G. Hepatitis C infection amongst blood donors in Punjab - a six year study. Indian J Hematol Blood Transfus 2001;19:21-2

[7]. Singh B, Verma M, Verma K. Markers of transfusion associated hepatitis in North Indian blood donors: Prevalence and trends. Jpn J Infect Dis 2004;57:49-51)

[8]. Gupta N, Vijay Kumar, Kaur A. Seroprevalence of HIV, HBV, HCV, and Syphilis in voluntary blood donors. Indian J Med Sci 2004;58:255-7

[9]. Chaudhary IA, Samiullah, Khan SS, Masood R, Sardar MA, Mallhi AA. Seroprevalence of HBV and C among health donors at Fauji Foundation Hospital, Rawalpindi. Pak Med J 2007;23:64-7.

[10]. Garg S, Mathur DR, Garg DK. Comparison of seropositivity of HIV, HBsAg, HCV and syphilis in replacement and voluntary blood donors in Western India. Indian J Pathol Microbiol 2001;44:409-12

[11]. Mumtaz S, Rehman MU, Muzaffar M, Hassan MU, Iqbal W. Frequency of seropositive blood donors for hepatitis B, C and HIV viruses in railway hospital, Rawalpindi. Pak J Med Res 2002;41(2):19-2

[12]. Dessie A, Abera B, Fissehawale. Seroprevalence of major blood borne infections among blood donors at Felege Hiwot referral hospital, Northwest Ethopia. Ethiop J Health Dev 2007;21:68-9.

[13]. Bagga PK, Singh SP. Seroprevalence of hepatitis C antibodies in healthy blood donors-a prospective study. Indian J Pathol Microbiol 2007;50:429-32

[14]. Mumtaz S, Rehman MU, Muzaffar M, Hassan MU, Iqbal W. Frequency of seropositive blood donors for hepatitis B, C and HIV viruses in railway hospital, Rawalpindi. Pak J Med Res 2002;41(2):19-2

[15]. Karkee S, Ghimire P, Tiwari B, Shrestha A. Seroprevalence of HIV and Hepatitis C coinfection among blood donors in Katmando valley, Nepal. Southeast Asian J Trop Med Public Health 2009;40(1):66-70) 0.26\%,

[16]. Matee M, Magesa PM, Lyamuya EF. Seroprevalence of human immunodeficiency virus, Hepatitis B and C viruses and Syphilis infections among blood donors at the Muhimbiili National Hospital in Dar es Salam, Tanzania. BMC Public Health 2006;6:21

[17]. Tiwari B, Ghimire P, Karkee S, Rajkarnikar M. Seroprevalence of human immunodeficiency Virus in Nepalese blood donors: A study from three regional blood transfusion services. Asian J Transf Sci 2008;2:66-8 